\title{
Antitumor activity of docetaxel-loaded polymeric nanoparticles fabricated by Shirasu porous glass membrane-emulsification technique
}

This article was published in the following Dove Press journal:

International Journal of Nanomedicine

26 July 2013

Number of times this article has been viewed

\author{
Yunni Yul,* \\ Songwei Tan ${ }^{1,2, *}$ \\ Shuang Zhao' \\ Xiangting Zhuang' \\ Qingle Song' \\ Yuliang Wang' \\ Qin Zhou ${ }^{2,3}$ \\ Zhiping Zhang ${ }^{1,2}$ \\ 'Tongji School of Pharmacy, ${ }^{2}$ National \\ Engineering Research Center for \\ Nanomedicine, ${ }^{3}$ College of Life \\ Science and Technology, Huazhong \\ University of Science and Technology, \\ Wuhan, People's Republic of China \\ *These authors contributed equally \\ to this work
}

\begin{abstract}
Docetaxel (DTX) has excellent efficiency against a wide spectrum of cancers. However, the current clinical formulation has limited its usage, as it causes some severe side effects. Various polymeric nanoparticles have thus been developed as alternative formulations of DTX, but they have been mostly fabricated on a laboratory scale. Previously, we synthesized a novel copolymer, poly(lactide)-D- $\alpha$-tocopheryl polyethylene glycol 1000 succinate (PLATPGS), and found that it exhibited great potential in drug delivery with improved properties. In this study, we applied the Shirasu porous glass (SPG) membrane-emulsification technique to prepare the DTX-loaded PLA-TPGS nanoparticles on a pilot scale. The effect of several formulation variables on the DTX-loaded nanoparticle properties, including particle size, zeta potential, and drug-encapsulation efficiency, were investigated based on surfactant type and concentration in the aqueous phase, organic/aqueous phase volumetric ratio, membrane-pore size, transmembrane cycles, and operation pressure. The DTX-loaded nanoparticles were obtained with sizes of $306.8 \pm 5.5 \mathrm{~nm}$ and $334.1 \pm 2.7 \mathrm{~nm}$ (mean value \pm standard deviation), and drugencapsulation efficiency of $81.8 \% \pm 4.5 \%$ and $64.5 \% \pm 2.7 \%$ for PLA-TPGS and poly(lacticco-glycolic acid) (PLGA) nanoparticles, respectively. In vivo pharmacokinetic study exhibited a significant advantage of PLA-TPGS nanoparticles over PLGA nanoparticles and Taxotere. Drug-loaded PLA-TPGS nanoparticles exhibited 1.78-, 6.34- and 3.35-fold higher values for area under the curve, half-life, and mean residence time, respectively, compared with those of PLGA nanoparticles, and 2.23-, 13.2-, 8.51-fold higher than those of Taxotere, respectively. In vivo real-time distribution of nanoparticles was measured on tumor-bearing mice by near-infrared fluorescence imaging, which demonstrated that the PLA-TPGS nanoparticles achieved much higher concentration and longer retention in tumors than PLGA nanoparticles after intravenous injection. This is consistent with the pharmacokinetic behavior of the nanoparticles. The tumorinhibitory effect of DTX-loaded nanoparticles was observed in vivo in an H22 tumor-bearing mice model via intravenous administration. This indicated that PLA-TPGS nanoparticles are a feasible drug-delivery formulation with a pilot fabrication technique and have superior pharmacokinetic and anticancer effects compared to the commercially available Taxotere.
\end{abstract}

Keywords: SPG membrane emulsification, nanoparticles, docetaxel, pharmacokinetics, antitumor activity

\section{Introduction}

Docetaxel (DTX), well known for its anticancer properties for over a decade, has excellent therapeutic efficiency against a wide spectrum of cancers. ${ }^{1,2}$ However, its poor water solubility limits its clinical use. ${ }^{3}$ The currently available dosage formulation is as an injection with Tween 80 and anhydrous ethanol as the cosolvents, which have been proved to cause some severe side effects. ${ }^{1,4}$ It is essential to develop a drug-delivery 
system (DDS) that will reduce the side effects and improve its therapeutic efficiency. Nanotechnology is being widely applied, and the nanocarriers for drug can not only increase drug solubility but also accumulate in tumor tissue through the well-known enhanced-permeability-and-retention effect. ${ }^{5}$ As a result, the therapeutic effects can be greatly improved. Many nanosized DTX formulations, such as liposomes, prodrugs, polymeric nanoparticles, and micelles, have been investigated and shown improved therapeutic efficiency. ${ }^{3,6-12}$ Among these, polymeric nanoparticles have been found to offer better stability, high drug-loading efficiency (DLE), small particle size, and preferable in vivo pharmacokinetics/pharmacodynamics. ${ }^{13,14}$ Poly(lactic acid) (PLA) and poly(lactide-co-glycolide) (PLGA) have been widely used in DDS because they are approved as good biodegradability and biocompatibility agents by the US Food and Drug Administration (FDA) ${ }^{15,16}$ However, the disadvantages of hydrophobicity and fast clearance after injection have limited their applications in vivo. ${ }^{17}$ To overcome these drawbacks, we designed a novel biodegradable copolymer: PLA-D- $\alpha$-tocopheryl polyethylene glycol 1000 succinate (PLA-TPGS). ${ }^{13}$ TPGS has been widely investigated for its emulsifying, dispersing, gelling, and solubilizing effects on poorly water-soluble drugs. It can also act as a P-glycoprotein inhibitor, and has served as an excipient for overcoming multidrug resistance and for increasing the oral bioavailability of many anticancer drugs. Since TPGS has been approved by the FDA as a safe pharmaceutic adjuvant, many TPGS-based DDSs have been developed. The PLA-TPGS copolymer brings the special properties of TPGS, and the resultant PLA-TPGS nanoparticles have exhibited superiority over ordinarily used PLGA nanoparticles, eg, long circulation time in vivo after intravenous administration, enhanced oral bioavailability, and increased cellular uptake by cancer cells. ${ }^{18,19}$

Although PLA-TPGS nanoparticles are reported to possess many advantages and have shown great potential in clinical use, their fabrication methods have been based on lab-scale methods, such as solvent extraction/evaporation, nanoprecipitation, and dialysis. ${ }^{18,20,21}$ This limits their applications in clinical therapy, due to the nonreplicability on the pilot scale. Recently, some new methods have been developed, including a newly upgraded microfluidic method, ${ }^{17,18}$ particle replication in nonwetting templates, ${ }^{19}$ and membrane-emulsification techniques ${ }^{20}$ to produce a uniform and controlled-size nanoparticle and show potential in pilot-scale production. The membrane-emulsification technique, also called the Shirasu porous glass (SPG) membrane-emulsification technique, which was proposed by Nakashima et al, ${ }^{22}$ has been widely used to produce microcapsules/microspheres, ${ }^{23,24}$ nanocapsules/nanoparticles, ${ }^{23,25}$ nanoemulsions, ${ }^{26}$ and liposome ${ }^{27}$ with sharp size distribution. SPG membrane is more effective than classical membranes because of its material and regenerative properties. ${ }^{28}$ It is also feasible for more advanced preparation of nanoparticles, with reduced cost and good productivity and reproducibility. ${ }^{29}$

In this study, the aim was to bring DTX-loaded PLATPGS nanoparticles from the lab scale to the pilot scale by SPG membrane emulsification. Variable parameters have been investigated on optimization, including surfactant type and concentration in the aqueous phase, organic/aqueous phase volumetric ratio, membrane-pore size, transmembrane cycles, and operation pressure. Optimized lab-scale formulation parameters would be used to produce PLA-TPGS and PLGA nanoparticles on a large scale for animal tests. Particle size, polydispersity index (PDI), encapsulation efficiency (EE) of the drug, and in vitro drug release of the nanoparticles were characterized. The antitumor efficiency, in vivo pharmacokinetics, and distribution of DTX-loaded PLA-TPGS nanoparticles were also measured in comparison with DTX-loaded PLGA nanoparticles and commercial drug formulations of Taxotere.

\section{Materials and methods Materials}

DTX ( $>99.9 \%$, Figure 1) was supplied by Jinhe Biotechnology, Hohhot, People's Republic of China, PLGA (Resomer $\mathrm{RG} 503 \mathrm{H}$ ) was procured from Boehringer Ingelheim, Ingelheim, Germany. Pluronic F68, TPGS, polyvinyl alcohol (PVA; molecular weight 30,000-70,000), DIR iodide (1,1'-dioctadecyl-3,3,3',3'-tetramethylindotricarbocyanine iodide, an insoluble near-infrared fluorescence dye; Figure 1), and dichloromethane (DCM) were purchased from SigmaAldrich, St Louis, MO, USA. Methanol and acetonitrile of high-performance liquid chromatography (HPLC) grade were supplied by Tang Ying (Fairfield, OH 50372, Japan). SPG membrane was bought from SPG Technology (Miyazaki, Japan). The SPG membrane device was supplied by the Institute of Process Engineering, Chinese Academy of Sciences.

Murine hepatic carcinoma cell line $\mathrm{H} 22$ was purchased from the Shanghai Institute of Cell Biology (Shanghai, People's Republic of China). Male Sprague Dawley rats of weight $200 \pm 20 \mathrm{~g}$ and Kunming mice of weight $20 \pm 2 \mathrm{~g}$ were purchased from the laboratory animal center of Huazhong University of Science and Technology (Wuhan, People's Republic of China). They were kept at a temperature of 


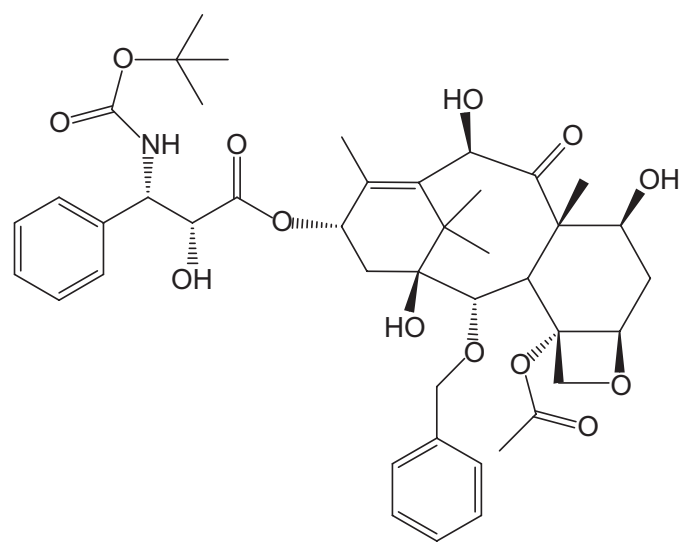

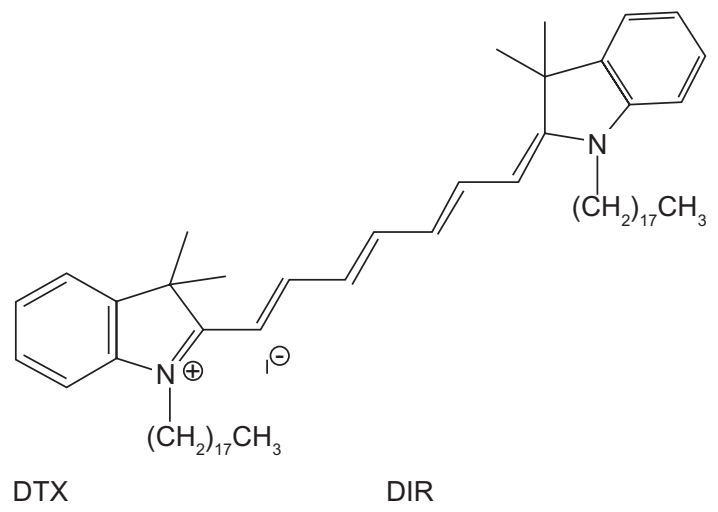

Figure I Chemical structure of docetaxel (DTX) and I, I'-dioctadecyl-3,3,3',3'tetramethylindotricarbocyanine iodide (DIR).

$25^{\circ} \mathrm{C} \pm 1{ }^{\circ} \mathrm{C}$, relative humidity of $50 \%-60 \%$ and in 12 -hour light-dark cycles. All the animals were starved for 12 hours before the experiment. All animal tests were performed in accordance with the institutional ethics committee regulations and guidelines on animal welfare.

\section{Synthesis of PLA-TPGS copolymer}

PLA-TPGS copolymer was synthesized by ring-opening synthesis of lactide monomer and TPGS with stannous octoate as the catalyst (Figure 2). The selected weight ratio of lactide:TPGS was 15:85. Lactide (10.2 g), TPGS (1.8 g), and $0.5 \%$ stannous octoate $(0.06 \mathrm{~g})$ were added to a $20 \mathrm{~mL}$ ampoule. The mixture was evacuated and sealed off in a nitrogen atmosphere. Then, the ampoule was heated in a silicone-oil bath for 12 hours at $145^{\circ} \mathrm{C}$. The reacted product was dissolved in DCM and precipitated in cold methanol to remove the unreacted lactide and TPGS. The final products were vacuum-dried at $45^{\circ} \mathrm{C}$ for 2 days and characterized by hydrogen-1 nuclear magnetic resonance ( $\left.{ }^{1} \mathrm{H}-\mathrm{NMR}\right)$ (ACF300; Bruker, Billerica, MA, USA) analysis. Yield was $74.1 \%$.

\section{Preparation of DTX-loaded nanoparticles by SPG emulsification technique}

The experimental setup of SPG membrane emulsification includes an inlet orifice, premix reservoir, a pressure vessel, SPG membrane, and an outlet orifice (Figure 3A). The membrane was ultrasonicated in deionized water for 30 minutes before operation. DTX-loaded nanoparticles were prepared by combining pre-emulsification and SPG membrane-emulsification methods. The organic phase containing polymer $(15 \mathrm{mg} / \mathrm{mL})$ and DTX (5 $\mathrm{wt} \%)$ was added into the aqueous phase with a certain amount of surfactant by magnetic stirring to get the coarse emulsions. Then, the premix emulsions were poured into the membrane apparatus. By virtue of the extra nitrogen pressure, the emulsions passed through the membrane to form homogeneous droplets. The flow of the emulsions across the membrane is described in Figure 3B.

The nanoparticle suspension was collected from the discharge orifice and then stabilized overnight under magnetic stirring. The suspension was centrifuged at $11,500 \mathrm{rpm}$ for 30 minutes and washed three times by continuous centrifugation to remove the surfactant and free drug. The channel and membrane were washed using ethyl acetate and deionized water after the process. The SPG membrane can be further regenerated under ultrasonication and high temperature. The preparation of nanoparticles was repeated three times. The SPG membrane dimensions were as follows: $0.125 \mathrm{~m}$ in length, $10 \mathrm{~m}^{-2}$ in inner diameter, and $10 \mathrm{~m}^{-3}$ in thickness. The nanoparticles were prepared under different conditions,

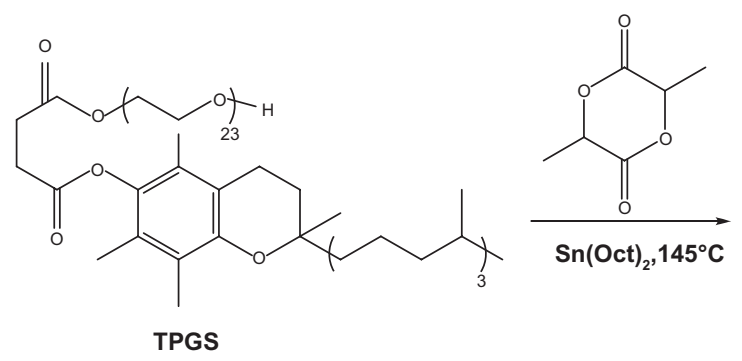

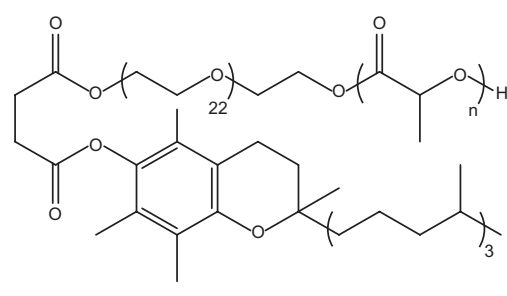

TPGS-b-PLA

Figure 2 Synthetic route of poly(lactide)-D- $\alpha$-tocopheryl polyethylene glycol 1000 succinate (PLA-TPGS). 

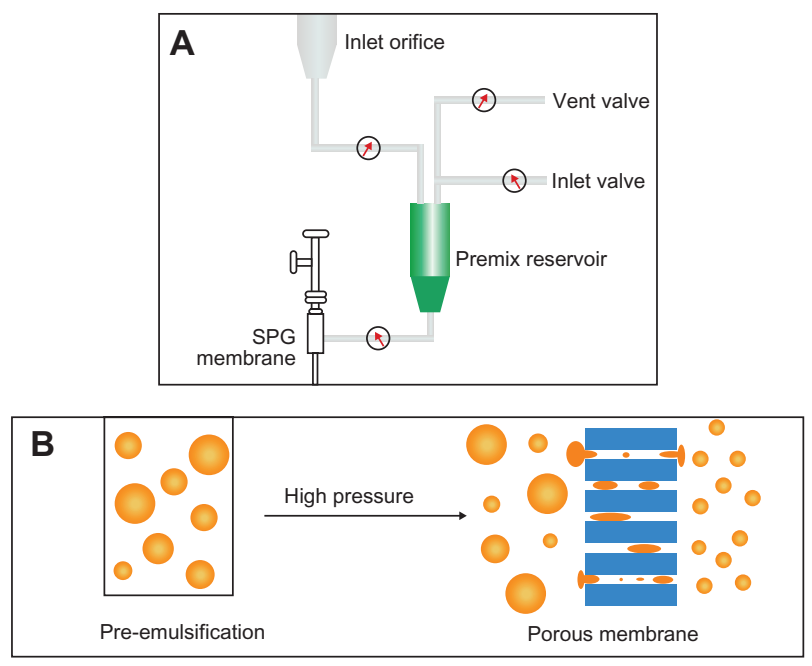

Figure 3 (A and B) Schematic diagram of Shirasu porous glass (SPG) membrane emulsification. (A) SPG membrane-emulsification apparatus; (B) membraneemulsification principle.

being: kinds of surfactant (PVA, TPGS, and F68), the volumetric ratio of organic phase to aqueous phase $(1: 10,1: 15$, and 1:20), transmembrane cycles (1,2,3,4, and 5), operation pressure $(0.6,1.0$, and $1.2 \mathrm{MPa})$, and pore sizes of membrane $(0.5 \mu \mathrm{m}, 0.8 \mu \mathrm{m}, 1.0 \mu \mathrm{m}$, and $1.5 \mu \mathrm{m})$.

\section{Nanoparticle characterization}

\section{Particle size, size distribution, and zeta potential}

The prepared nanoparticles were measured by laser light scattering (DB-525 ZetaPALS; Brookhaven Instruments, Holtsville, NY, USA) for particle size, size distribution, and zeta potential. A typical result was obtained based on the average from three runs, and the measurement was performed at $20^{\circ} \mathrm{C}$.

\section{Drug-encapsulation efficiency}

The quantitative analysis of DTX was done by HPLC (L-2000; Hitachi, Tokyo, Japan). A reverse-phase Inertsil ODS-3 $\mathrm{C}_{18}$ column $(150 \times 4.6 \mathrm{~mm}$, pore size $5 \mu \mathrm{m}$; Agilent Technologies, Santa Clara, CA, USA) was used. The flow rate of the mobile phase was $1 \mathrm{~mL} /$ minute, and the column effluent was detected at $227 \mathrm{~nm}$ with an ultraviolet detector. Three milligrams of nanoparticles were dissolved in $1 \mathrm{~mL}$ DCM, and then volatilized in a fume hood overnight. Two milliliters of mobile phase (acetonitrile/water solution $50 / 50, \mathrm{v} / \mathrm{v}$ ) was added to reconstitute the sample. The solution was centrifuged at 11,500 rpm for 5 minutes, and the supernatant was further filtered through a $0.22 \mu \mathrm{m}$ membrane before HPLC analysis. EE was obtained from the weight ratio between the drug entrapped in nanoparticles and that used in the fabrication. DLE was also considered, as shown in formula (2). EE is a good index on drug encapsulation in nanoparticles on the lab scale. DLE exhibits good indication on drug recovery from fabrication for the pilot scale.

$\mathrm{EE}=\frac{\text { Amount of drug loaded in nanoparticle }}{\text { Theoretical amount of drug in nanoparticle }} \times 100 \%$

$\begin{aligned} \text { DLE }= & \frac{\text { Total amount of drug recovered in nanoparticles }}{\text { Total amount of drug in feeding }} \\ & \times 100 \%\end{aligned}$

\section{In vitro release behavior}

To determine the in vitro drug-release behavior, $15 \mathrm{mg}$ of the DTX-loaded nanoparticles was dispersed into $5 \mathrm{~mL}$ of phosphate-buffered saline (PBS) solution of $\mathrm{pH} 7.4$ to form a suspension. The suspension was then put into a dialysis bag (molecular weight cutoff 3,500 Da) containing $50 \mathrm{~mL}$ PBS as dialysis solution and transferred into a $37.2^{\circ} \mathrm{C}$ water bath shaking at $120 \mathrm{rpm}$. At allocated time intervals, $10 \mathrm{~mL}$ of dialysis solution was withdrawn, and this volume replaced by the addition of fresh PBS into the setup. The DTX concentration was determined by the same procedure as EE. ${ }^{13}$

\section{Pharmacokinetic study}

The pharmacokinetics of Taxotere- and DTX-loaded nanoparticles was studied using male Sprague Dawley (SD) rats weighing $200 \pm 20 \mathrm{~g}$. The SD rats were divided into three groups $(n=4)$. The rats were injected intravenously with Taxotere, DTX-loaded PLGA, and PLA-TPGS nanoparticles, at a dose of DTX $10 \mathrm{mg} / \mathrm{kg}$ each. Blood samples were collected into Eppendorf tubes with heparin at 30 minutes and 1, 2, 4, 8, 12, and 24 hours for the Taxotere group and further collected for DTX-loaded nanoparticle groups after 2, 3, 5, 7, 10, and 14 days. The collected blood samples were centrifuged to obtain the plasma and stored at $-20^{\circ} \mathrm{C}$ until analysis. The DTX concentrations in plasma were analyzed by HPLC with norethindrone as the internal standard added to the plasma sample. Then, the mixture was extracted by $1 \mathrm{~mL}$ methyl tertiary butyl ether and vortexed for 5 minutes. Upon centrifugation at 11,000 rpm for 5 minutes, the supernatant was collected and dried at $37^{\circ} \mathrm{C}$ using a N-EVAP MTN-2800D (AutoScience, Tianjin, People's Republic of China). The residue was dissolved in the mobile phase (acetonitrile/ water solution, 50/50, v/v), and centrifuged at 11,000 rpm for 5 minutes. Twenty microliters of supernatant was 
used for the analysis. The standard curve was linear and ranged from 0.05 to $50 \mu \mathrm{g} / \mathrm{mL}\left(R^{2}=0.9991\right)$. The analysis was operated by an Agilent system with a Hypersil ODS column $(5 \mu \mathrm{m}, 4.6 \times 150 \mathrm{~mm})$ at $30^{\circ} \mathrm{C}$ with the wavelength set at $227 \mathrm{~nm}$. The mobile phase was acetonitrile and water $(50 / 50, \mathrm{v} / \mathrm{v})$ at a rate of $1.0 \mathrm{~mL} / \mathrm{minute}$. The pharmacokinetic parameters were calculated by the drug and statistics (DAS) software (version 2.1.1; Mathematical Pharmacology Professional Committee, Shanghai, People's Republic of China).

\section{In vivo biodistribution}

DIR-loaded nanoparticles were fabricated by a similar procedure as DTX-loaded nanoparticles and used to investigate the biodistribution in the armpit of tumors of $\mathrm{H} 22$ cell-bearing male mice. The H22 hepatic cancer cells $\left(2 \times 10^{6}\right.$ cells/ mouse) were subcutaneously transplanted into the right axilla of mice. When the tumor volume reached a size of about $150 \mathrm{~mm}^{3}$, the mice were injected with physiological saline, DIR-loaded PLGA, and PLA-TPGS nanoparticles at a dose of DIR $0.1 / \mathrm{kg}$ body weight via the tail vein. The animals were anesthetized by isoflurane inhalation. Fluorescence of injected DIR-loaded nanoparticles was visualized using Caliper IVIS in vivo fluorescence imaging system (Lumina XR; PerkinElmer, Waltham, MA, USA) with an excitation filter at $704 \mathrm{~nm}$ and an emission filter at $750 \mathrm{~nm}$. Scans were conducted at 1, 2, 4, 6, 8, and 24 hours after intravenous administration. Exposure time was 1,000 milliseconds per cube. After in vivo imaging, the mice were killed at 24 hours, and heart, liver, spleen, lungs, kidneys, and tumors were excised. The near-infrared fluorescence-signal intensities in different tissues were obtained.

\section{Tumor-growth inhibition}

The animal model used was H22-transplanted solid tumorbearing mice (5-7 weeks old, 18-20 g). The mice were subcutaneously injected at the lower right axilla with $0.1 \mathrm{~mL}$ H22 cell suspension containing $10^{7}$ cells. After inoculation, the tumor volume in each mouse was closely watched and measured by vernier calipers every day and calculated as $\mathrm{L} \times \mathrm{W}^{2} / 2$, where $\mathrm{W}$ is the width and $\mathrm{L}$ is the tumor length. The mice were randomly divided into four groups $(n=7)$ after the tumor volume grew to $100-150 \mathrm{~mm}^{3}$. This was noted as day 1 . The mice were injected intravenously through the tail vein with saline, Taxotere, and DTX-loaded PLA-TPGS and PLGA nanoparticles at a dose of $10 \mathrm{mg} / \mathrm{kg}$ on days 1 , 3,5 , and 7. Tumor size was measured every day to evaluate antitumor efficiency. To monitor potential toxicity, the body weight of each mouse was also measured every day. For humane reasons, mice were killed when tumor length increased beyond $20 \mathrm{~mm}$.

\section{Statistical analysis}

Data were expressed as means \pm standard deviation. Paired two-tailed Student's $t$-tests were used to compare quantitative data. Tumor growth was statistically evaluated by repeated measures. If the $P$-value was less than 0.05 , the differences were considered significant.

\section{Results and discussion}

\section{The synthesis and characterization} of PLA-TPGS copolymer

The synthesized PLA-TPGS copolymer was characterized by ${ }^{1} \mathrm{H}-\mathrm{NMR}$ (Figure 4). The signals at 5.2, 1.69, and 3.65 ppm were assigned to the $-\mathrm{CH}$ protons, methyl proton $-\mathrm{CH}_{3}$ of PLA, and $-\mathrm{CH}_{2}$ protons of the polyethylene glycol part of TPGS, respectively. The other peaks of TPGS could be also noted in the spectrum. The average molecular weight calculated from NMR was 11,000, which was a little higher than the theoretical Mn of PLA-TPGS $(10,013)$. This may have been caused by the existence of di-TPGS $(\sim 10 \%)$ in commercial TPGS, which could not induce ring-opening polymerization.

\section{Effects of process variables on preparation of DTX-loaded nanoparticles Effects of surfactant quantity and type}

The emulsifier is vital to the preparation of nanoparticles by the SPG membrane technique, as it affects

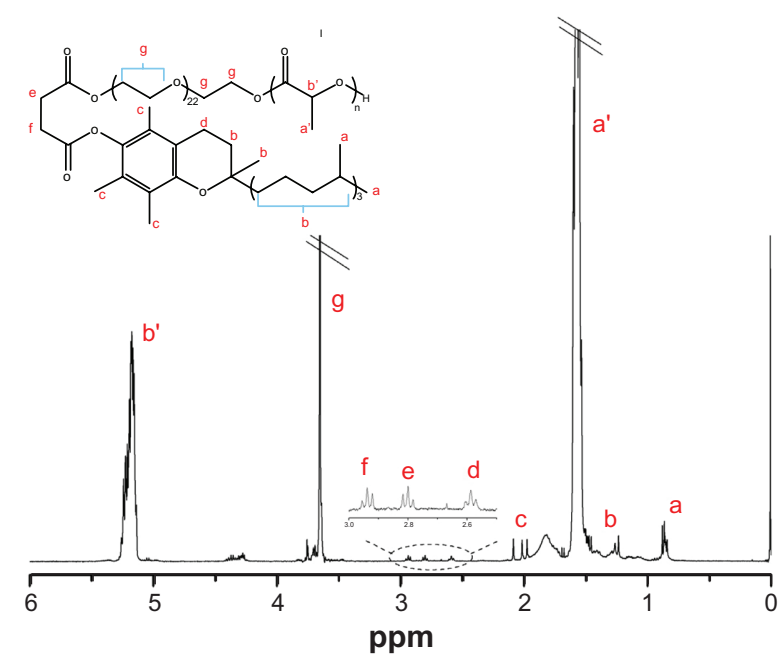

Figure 4 Hydrogen-I nuclear magnetic resonance spectrum of poly(lactide)-D- $\alpha$ tocopheryl polyethylene glycol I,000 succinate.

Abbreviation: ppm, parts per million. 
the viscosity of the formulation and interfacial tension between the organic phase and aqueous phase. ${ }^{26,30} \mathrm{~A}$ typical surfactant, PVA, was used to investigate the effects of surfactant concentrations in the aqueous phase. The results are shown in Table 1 . With the increase in PVA concentration, the nanoparticles became smaller and more homogeneous. ${ }^{31}$ This is because the surfactant was able to form a molecular layer in the oil-water interface, which protected the nanoparticles from aggregation. However, sizes increased again if the concentration was higher than 1\%. PVA concentration that is too high may increase the viscosity of preemulsion and difficulty in passing through the membrane pores. This increases by two- to fivefold the duration required to prepare a similar amount of nanoparticle emulsion. Furthermore, the DLE values significantly decreased from $48.4 \% \pm 3.3 \%$ for $0.5 \%$ PVA-emulsified nanoparticles to $32.7 \% \pm 2.8 \%$ and $29.3 \% \pm 3.1 \%$ for $1 \%$ and $2 \%$ PVA-emulsified nanoparticles, respectively. EE also decreased from $81.8 \% \pm 4.5 \%$ for $0.5 \%$ PVA-emulsified nanoparticles to $49.7 \% \pm 8.2 \%$ for $2 \%$ PVA-emulsified nanoparticles. Therefore, the optimized PVA concentration was fixed at $0.5 \%$ in the aqueous phase in our consecutive experiments.

Three principally used surfactants - PVA, TPGS, and Pluronic F68 - were investigated on fabricating nanoparticles. Surfactant concentrations chosen were $0.5 \%$, $1 \%$ and $2 \%$, respectively, according to our preliminary tests. The effects of the different surfactants on size, PDI, and EE are shown in Table 1. The nanoparticles prepared with TPGS and F68 as emulsifier had larger particle sizes with lower EE and DLE compared with PVA at the same concentration. PVA $0.5 \%$ in aqueous solution was selected as the preferred emulsifier.

\section{Effects of the volumetric ratio of organic phase to aqueous phase}

The results of PLGA nanoparticles prepared by different volumetric ratios are shown in Table 2. It is evident that the PDI and size reduced at higher volumetric ratios of organic phase to aqueous phase. This means that an increase in the volume of the water phase corresponded with a decrease in the concentration of emulsion. This prevents the nanoparticles from cracking and aggregation. ${ }^{32}$ Although particle size increased from $259.5 \pm 3.1 \mathrm{~nm}$ at a w/o ratio of 1:10 up to $306.8 \pm 5.5 \mathrm{~nm}$ at a w/o ratio of $1: 15$, EE and DLE were significantly enhanced from $53.0 \% \pm 3.7 \%$ and $29.9 \% \pm 4.8 \%$ to $81.8 \% \pm 4.5 \%$ and $48.4 \% \pm 3.3 \%$ at a ratio of $1: 15$, respectively. Furthermore, nanoparticles fabricated under the higher w/o ratio of 1:20 yielded the largest particle sizes and decreased DLE. Therefore, the optimized w/o ratio was chosen as 1:15 to get the highest EE and DLE and appropriate particle size.

\section{Effects of transmembrane cycles}

The effects of the transmembrane cycles are displayed in Table 3. At constant pressure, the most important factor in the determination of size and DLE was the transmembrane cycle. When the preemulsion passed through the membrane fewer than three times, the size would be more than $300 \mathrm{~nm}$ and the PDI above 0.1 . When the preemulsion passed through the membrane more than three times, more homogeneous

Table I Effects of surfactant type and surfactant concentration in aqueous phase in fabricating DTX-loaded PLA-TPGS nanoparticles on size, PDI, EE, and DLE

\begin{tabular}{llllrr}
\hline Surfactant & $\begin{array}{l}\text { Concentration } \\
(\mathbf{w t} \%)\end{array}$ & $\begin{array}{l}\text { Mean diameter } \\
(\mathbf{n m})\end{array}$ & PDI & EE (\%) & DLE (\%) \\
\hline PVA & 0.1 & $387.8 \pm 6.7$ & $0.210 \pm 0.340$ & $80.3 \pm 8.9$ & $17.1 \pm 2.1$ \\
& 0.5 & $306.8 \pm 5.5$ & $0.098 \pm 0.064$ & $81.8 \pm 4.5$ & $48.4 \pm 3.3$ \\
& 1 & $250.6 \pm 15.7$ & $0.078 \pm 0.018$ & $63.8 \pm 7.1$ & $32.7 \pm 2.8$ \\
& 2 & $237.6 \pm 13.5$ & $0.104 \pm 0.023$ & $49.7 \pm 8.2$ & $29.3 \pm 3.1$ \\
F68 & 0.5 & $435.8 \pm 15.0$ & $0.162 \pm 0.061$ & $30.9 \pm 3.3$ & $2.2 \pm 1.0$ \\
& 1 & $397.0 \pm 5.0$ & $0.195 \pm 0.020$ & $21.8 \pm 1.6$ & $5.6 \pm 4.8$ \\
& 2 & $346.8 \pm 4.9$ & $0.235 \pm 0.072$ & $1.9 \pm 4.9$ & $3.9 \pm 2.3$ \\
TPGS & 0.5 & $306.8 \pm 6.3$ & $0.125 \pm 0.076$ & $3.2 \pm 5.7$ & $3.2 \pm 1.8$ \\
& 1 & $275.1 \pm 4.5$ & $0.005 \pm 0.002$ & $27.4 \pm 1.7$ & $7.2 \pm 1.5$ \\
& 2 & $256.1 \pm 8.7$ & $0.004 \pm 0.003$ & $16.9 \pm 2.2$ & $4.9 \pm 1.3$ \\
\hline
\end{tabular}

Notes: The volumetric ratio of organic phase to aqueous phase was I:I5 (v/v), the membrane-pore size was I.0 $\mu \mathrm{m}$, and the transmembrane pressure was I.0 MPa in three cycles.

Abbreviations: PLA-TPGS, poly(lactide)-D- $\alpha$-tocopheryl polyethylene glycol 1000 succinate; DTX, docetaxel; PVA, polyvinyl alcohol; PDI, polydispersity index; $\mathrm{EE}$, encapsulation efficiency; DLE, drug-loading efficiency; F68, pluronic; TPGS, $d$ - $\alpha$-tocopheryl polyethylene glycol 1000 succinate. 
Table 2 Effects of volumetric ratio of organic to aqueous phase in fabricating DTX-loaded PLA-TPGS nanoparticles on size, PDI, $\mathrm{EE}$, and DLE

\begin{tabular}{lllll}
\hline Ratio & $\begin{array}{l}\text { Mean } \\
\text { diameter }(\mathbf{n m})\end{array}$ & PDI & EE (\%) & DLE (\%) \\
\hline $\mathrm{I}: 10$ & $259.5 \pm 3 . \mathrm{I}$ & $0.12 \mathrm{I} \pm 0.018$ & $53.0 \pm 3.7$ & $29.9 \pm 4.8$ \\
$\mathrm{I}: 15$ & $306.8 \pm 5.5$ & $0.098 \pm 0.064$ & $81.8 \pm 4.5$ & $48.4 \pm 3.3$ \\
$\mathrm{I}: 20$ & $335.8 \pm 3.7$ & $0.029 \pm 0.009$ & $80.7 \pm 5.4$ & $27.2 \pm 3.5$ \\
\hline
\end{tabular}

Notes: The concentration of PVA was $0.5 \%$, the membrane-pore size was $1.0 \mu \mathrm{m}$, and the pressure was $1.0 \mathrm{MPa}$ in three cycles.

Abbreviations: PLA-TPGS, poly(lactide)-D- $\alpha$-tocopheryl polyethylene glycol 1000 succinate; DTX, docetaxel; PVA, polyvinyl alcohol; PDI, polydispersity index; EE, encapsulation efficiency; DLE, drug-loading efficiency.

nanoparticles formulated. This may be attributed to the fact that every time the emulsion passes through the membrane, the big liquid drops get crushed into smaller drops by the shearing force between the liquid drops and pores. The more times the emulsion passed through the membrane, the smaller the sizes obtained. However, particle recovery decreased sharply after the preemulsion passed though the membrane more than three times. The DLE also significantly decreased from $48.4 \% \pm 3.3 \%$ for three cycles to $20.7 \% \pm 6.1 \%$ for five cycles. This shows a similar trend to previous work. ${ }^{33}$ Based on size, particle uniformity, and DLE, three transmembrane cycles were applied in preparing the nanoparticles.

\section{Effects of transmembrane pressure}

The effect of transmembrane pressure was investigated by applying different pressures, as shown in Table 4. The pressure exhibited little effect on the PDI, but affected particle size and DLE. The higher the pressure, the smaller the particles obtained. ${ }^{26}$ High pressure causes a strong shear force and breaks preemulsion drops into smaller particles. However, exceedingly high transmembrane pressure may

Table 3 Effects of the transmembrane cycles in fabricating DTXloaded PLA-TPGS nanoparticles on size, PDI, EE, and DLE

\begin{tabular}{lllll}
\hline Cycles & $\begin{array}{l}\text { Mean } \\
\text { diameter }(\mathbf{n m})\end{array}$ & PDI & EE (\%) & DLE (\%) \\
\hline 1 & $461.9 \pm 10.6$ & $0.223 \pm 0.029$ & $18.9 \pm 3.0$ & $13.0 \pm 3.1$ \\
2 & $384.8 \pm 9.8$ & $0.134 \pm 0.012$ & $47.1 \pm 5.7$ & $28.6 \pm 2.6$ \\
3 & $306.8 \pm 5.5$ & $0.098 \pm 0.064$ & $81.8 \pm 4.5$ & $48.4 \pm 3.3$ \\
4 & $247.7 \pm 4.7$ & $0.005 \pm 0.003$ & $70.6 \pm 9.1$ & $31.9 \pm 3.0$ \\
5 & $236.1 \pm 2.0$ & $0.005 \pm 0.002$ & $71.8 \pm 7.7$ & $20.7 \pm 6.1$ \\
\hline
\end{tabular}

Notes: The concentration of polymer in the organic phase was $15 \mathrm{mg} / \mathrm{mL}$ with $5 \%$ drug loading, the concentration of PVA was $0.5 \%$, the membrane-pore size was $1.0 \mu \mathrm{m}$, and the transmembrane pressure was $1.0 \mathrm{MPa}$ in three cycles.

Abbreviations: PLA-TPGS, poly(lactide)-D- $\alpha$-tocopheryl polyethylene glycol 1000 succinate; DTX, docetaxel; PVA, polyvinyl alcohol; PDI, polydispersity index; EE, encapsulation efficiency; DLE, drug-loading efficiency.
Table 4 Effects of the transmembrane pressure in fabricating DTX-loaded PLA-TPGS nanoparticles on size, PDI, EE, and DLE

\begin{tabular}{lllll}
\hline $\begin{array}{l}\text { Pressure } \\
(\mathbf{M P a})\end{array}$ & $\begin{array}{l}\text { Mean } \\
\text { diameter }(\mathbf{n m})\end{array}$ & PDI & EE (\%) & DLE (\%) \\
\hline 0.6 & $339.1 \pm 5.1$ & $0.137 \pm 0.051$ & $62.0 \pm 6.8$ & $40.4 \pm 2.9$ \\
1.0 & $306.8 \pm 5.5$ & $0.098 \pm 0.064$ & $81.8 \pm 4.5$ & $48.4 \pm 3.3$ \\
1.2 & $257.8 \pm 3.6$ & $0.012 \pm 0.031$ & $71.9 \pm 8.5$ & $28.8 \pm 3.3$ \\
\hline
\end{tabular}

Notes: The concentration of polymer in the organic phase was $15 \mathrm{mg} / \mathrm{mL}$ and volumetric ratio of organic to aqueous phase was I: 15 with $5 \%$ drug loading, the concentration of PVA was $0.5 \%$, and the membrane-pore size was $1.0 \mu \mathrm{m}$ in three cycles.

Abbreviations: PLA-TPGS, poly(lactide)-D- $\alpha$-tocopheryl polyethylene glycol 1000 succinate; DTX, docetaxel; PVA, polyvinyl alcohol; PDI, polydispersity index; EE, encapsulation efficiency; DLE, drug-loading efficiency.

cause small droplets to be destroyed, resulting in low recovery. The highest EE and DLE values obtained were $81.8 \% \pm 4.5 \%$ and $48.4 \% \pm 3.3 \%$ for $1.0 \mathrm{MPa}$. Therefore, 1.0 MPa was selected to be the optimized transmembrane pressure.

\section{Effects of membrane pore}

The SPG membrane is the unit of breakup in the extrusion technique. When a marginal distribution of membrane pore sizes is used, uniform sized nanoparticles can be produced. ${ }^{31} \mathrm{~A}$ difference in membrane-pore size may affect the emulsion-disruption process and yield nanoparticles with nonuniform sizes. The experiment was conducted with four mean sizes of SPG membranes: $0.5 \mu \mathrm{m}, 0.8 \mu \mathrm{m}, 1 \mu \mathrm{m}$, and $1.5 \mu \mathrm{m}$. The particles fabricated after passing through different pore-size membranes are shown in Table 5. It is obvious that smaller nanoparticles were obtained with decreased membrane-pore sizes. ${ }^{30,34}$ Exceedingly small pore size of $0.5 \mu \mathrm{m}$ increased the duration of time to produce a similar amount of nanoparticles. On the other hand, a very large pore size caused larger and nonuniform particles.

Table 5 Effects of membrane-pore size in fabricating DTX-loaded PLA-TPGS nanoparticles on size, PDI, EE, and DLE

\begin{tabular}{lllll}
\hline $\begin{array}{l}\text { Pore } \\
\text { size }(\mu \mathrm{m})\end{array}$ & $\begin{array}{l}\text { Mean } \\
\text { diameter }(\mathbf{n m})\end{array}$ & PDI & EE (\%) & DLE (\%) \\
\hline 0.5 & ND & ND & ND & ND \\
0.8 & $272.8 \pm 4.8$ & $0.009 \pm 0.003$ & $60.4 \pm 6.3$ & $36.7 \pm 2.0$ \\
1.0 & $306.8 \pm 5.5$ & $0.098 \pm 0.064$ & $81.8 \pm 4.5$ & $48.4 \pm 3.3$ \\
1.5 & $437.1 \pm 18.5$ & $0.237 \pm 0.102$ & $77.9 \pm 6.7$ & $30.3 \pm 1.9$ \\
\hline
\end{tabular}

Notes: The concentration of polymer in the organic phase was $15 \mathrm{mg} / \mathrm{mL}$ with $5 \%$ drug loading, the volumetric ratio of organic to aqueous phase was I:I5, the concentration of PVA was $0.5 \%$, and the transmembrane pressure was $1.0 \mathrm{MPa}$ in three cycles. Abbreviations: ND, not determined (the small pore size of the membrane caused long duration to produce nanoparticles); PLA-TPGS, poly(lactide)-D- $\alpha$-tocopheryl polyethylene glycol 1000 succinate; DTX, docetaxel; PVA, polyvinyl alcohol; PDI, polydispersity index; EE, encapsulation efficiency; DLE, drug-loading efficiency. 
When compared, the particles obtained using a pore size of $0.8 \mu \mathrm{m}$ achieved higher EE than particles for $1.0 \mu \mathrm{m}$ pore size $(81.8 \% \pm 4.5 \%$ vs $60.4 \% \pm 6.3 \%)$ and DLE $(48.4 \% \pm 3.3 \%$ vs $36.7 \% \pm 2.0 \%)$, with acceptable particle size $(306.8 \pm 5.5 \mathrm{~nm}$ vs $272.8 \pm 4.8 \mathrm{~nm})$. The optimal pore size was selected as $1.0 \mu \mathrm{m}$.

\section{Comparisons of PLGA and PLA-TPGS polymers in fabricating nanoparticles}

Based on these results, the optimized experimental parameters were chosen as follows: volumetric ratio of organic to aqueous phase of $1: 15$, concentration of PVA of $0.5 \%$, membrane-pore size of $1.0 \mu \mathrm{m}$, and transmembrane pressure of 1.0 MPa in three cycles. The copolymer PLA-TPGS was compared with PLGA in fabricating DTX-loaded nanoparticles, as shown in Table 6. The PLA-TPGS nanoparticles exhibited higher EE and DLE values than PLGA nanoparticles, with relatively smaller particle size and uniformity due to their amphipathic property and large surface area of TPGS. ${ }^{35} \mathrm{EE}$ and DLE reached $81.8 \% \pm 4.5 \%$ and $48.4 \% \pm 3.3 \%$, respectively. This showed a similar tendency to the PLA-TPGS nanoparticles fabricated by dialysis and the solvent extraction-emulsion method, ${ }^{10,11}$ and was also close to other reported DTX-loaded nanoparticles, such as PEG-PLA nanoparticles (90.0\% EE), ${ }^{36}$ PEG-PLGA nanoparticles $\left(80.0 \%\right.$ EE), ${ }^{3}$ PEG-poly( $\varepsilon$-caprolactone) (PEG-PCL) nanoparticles $(80.7 \%),{ }^{14}$ and PCL-Tween 80 nanoparticles $(82.0 \%) .{ }^{11}$ Other formulations, such as liposome and micelle, were also reported with similar EE levels (70\%-90\% $\%^{31,37}$ and $60 \%-90 \%,{ }^{32,33}$ respectively). Scanning electron microscopy also showed that PLA-TPGS nanoparticles had a uniform shape (Figure 5). On the other hand, the productivity of this method was about $2 \mathrm{~g}$ PLA-TPGS (or PLGA) nanoparticles per hour, with high EE and reproducibility. As seen in Table 7, particle size, EE, and DLE exhibited similar values among different batches. The SPG membrane-emulsification technology is thus a suitable way to raise production of nanoparticles.

\section{In vitro release behavior}

The cumulative release profiles of DTX-loaded PLGA and PLA-TPGS nanoparticles are shown in Figure 6. The TPGS component affected release behavior in vitro. The initial burst release emerged after the first 24 hours, and maintained a relatively slow rate to the balance stage. In the first 24 hours, DTX-loaded PLGA nanoparticles released $68.0 \% \pm 2.1 \%$ of entrapped drug, which was twice as fast as that of PLA-TPGS nanoparticles. After 7 days, PLGA and PLA-TPGS nanoparticles released nearly $79.1 \% \pm 2.3 \%$ and $64.5 \% \pm 1.3 \%$ of entrapped drug, respectively. PLA-TPGS nanoparticles exhibit slower release rates and much lower burst release, which may decrease drug leakage from nanoparticles during nanoparticle circulation in the blood and reduce side effects. PLA-TPGS nanoparticles may cover the surface of nanoparticles by TPGS with their amphiphilic structure, which prevents water from getting into the nanoparticles.

\section{Pharmacokinetic study}

DTX-loaded polymeric nanoparticles and Taxotere were administered to mice at a dose of DTX $10 \mathrm{mg} / \mathrm{kg}$ by tail-vein injection. Blood samples were withdrawn at selected time intervals and analyzed for DTX concentration. The plasma concentration-time profiles are shown in Figure 7, and the corresponding pharmacokinetic parameters are summarized in Table 8. All plasma profiles were found to be in line with the two-compartment model. The blood-circulation time of PLA-TPGS nanoparticles was significantly extended compared to that of Taxotere, with a 13.2-fold longer half-life $\left(t_{1 / 2}\right), 8.51$-fold higher mean residence time (MRT), 2.23-fold higher area under the curve $\left(\mathrm{AUC}_{0-72}\right)$, and substantially lower values of clearance $(41.9 \%)$. These results indicated that the plasma pharmacokinetics of DTX given in the PLATPGS nanoparticle formulation were different from those of Taxotere. Compared with PLGA nanoparticles, PLA-TPGS nanoparticles also exhibited 1.78-, 6.34-, and 3.35-fold increases for $\mathrm{AUC}_{0-72}, t_{1 / 2}$, and MRT, respectively. In Taxotere treatment, high levels of free DTX were measured at reduced

Table 6 Effects of PLGA and PLA-TPGS copolymer in fabricating DTX-loaded nanoparticles on size, PDI, EE, and DLE

\begin{tabular}{llllll}
\hline Polymer & $\begin{array}{l}\text { Mean } \\
\text { diameter }(\mathbf{n m})\end{array}$ & PDI & EE (\%) & DLE (\%) & $\begin{array}{l}\text { Zeta } \\
\text { potential (mv) }\end{array}$ \\
\hline PLGA & $334.1 \pm 2.7$ & $0.013 \pm 0.005$ & $64.5 \pm 2.7$ & $38.8 \pm 5.6$ & $-16.4 \pm 1.0$ \\
PLA-TPGS & $306.8 \pm 5.5$ & $0.098 \pm 0.064$ & $81.8 \pm 4.5$ & $48.4 \pm 3.3$ & $-22.8 \pm 0.7$ \\
\hline
\end{tabular}

Notes: The concentration of polymer in the organic phase was $15 \mathrm{mg} / \mathrm{mL}$ with $5 \%$ drug loading, the volumetric ratio of organic to aqueous phase was I:I5, the concentration of PVA was $0.5 \%$, the membrane-pore size was $1.0 \mu \mathrm{m}$, and the transmembrane pressure was $1.0 \mathrm{MPa}$ in three cycles.

Abbreviations: PLA-TPGS, poly(lactide)-D- $\alpha$-tocopheryl polyethylene glycol 1000 succinate; PLGA, poly(lactic-co-glycolic acid); DTX, docetaxel; PVA, polyvinyl alcohol; PDI, polydispersity index; EE, encapsulation efficiency; DLE, drug-loading efficiency. 


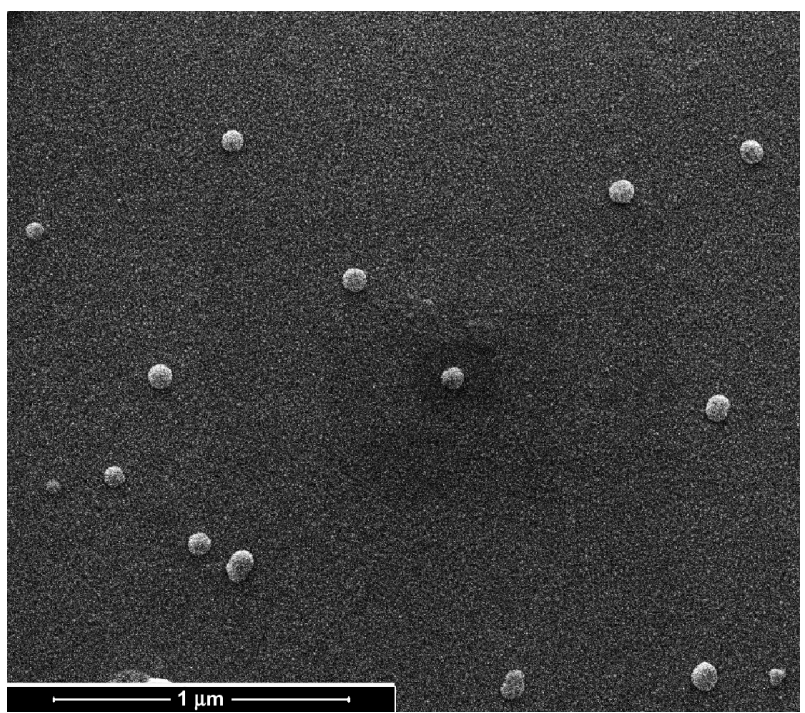

Figure 5 Scanning electron microscopy image of poly(lactide)-D- $\alpha$-tocopheryl polyethylene glycol I,000 succinate nanoparticles.

time intervals, up to 3 hours. The remaining DTX could not be detected, as the plasma concentration became less than $0.035 \mu \mathrm{g} / \mathrm{mL}$ (which was considered as the minimum effective concentration of DTX ${ }^{38}$ ) in Taxotere within 24 hours. The DTX content was rapidly washed out or metabolized. It was reported that the uptake of nanoparticles by reticuloendothelial system organs following intravenous injection might take between a few minutes to hours, depending on particle size and composition. The PLA-TPGS nanoparticles exhibited a significantly longer retention time in the blood compared to Taxotere and PLGA nanoparticles. The results are of a similar tendency as previously reported. ${ }^{18,21,38}$

\section{In vivo biodistribution}

Biodistribution of the PLA-TPGS and PLGA nanoparticles were studied by molecular imaging and shown in Figure 8. Figure 8A represents the real-time distribution and tumor-accumulation ability of fluorescence DIR-loaded nanoparticles in the armpit tumors of mice. Visible fluorescence accumulation was found in tumor-bearing mice of the PLA-TPGS nanoparticle-treated group from 4 hours

Table 7 Properties of PLA-TPGS nanoparticles on a pilot scale

\begin{tabular}{lllll}
\hline Batch & $\begin{array}{l}\text { Mean } \\
\text { diameter }(\mathbf{n m})\end{array}$ & PDI & EE (\%) & DLE (\%) \\
\hline 1 & $295.7 \pm 6.1$ & $0.047 \pm 0.005$ & $83.2 \pm 4.3$ & $44.5 \pm 2.4$ \\
2 & $301.9 \pm 5.8$ & $0.056 \pm 0.018$ & $85.7 \pm 3.8$ & $46.1 \pm 3.1$ \\
3 & $306.8 \pm 5.5$ & $0.098 \pm 0.064$ & $81.8 \pm 4.5$ & $48.4 \pm 3.3$ \\
\hline
\end{tabular}

Abbreviations: PLA-TPGS, poly(lactide)-D- $\alpha$-tocopheryl polyethylene glycol 1000 succinate; PDI, polydispersity index; EE, encapsulation efficiency; DLE, drug-loading efficiency.

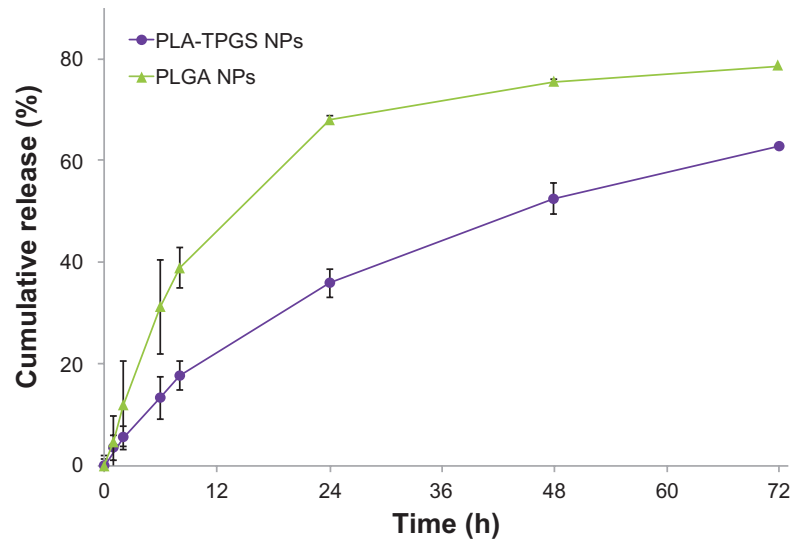

Figure 6 Cumulative release profiles of docetaxel-loaded poly(lactide)-D- $\alpha$ tocopheryl polyethylene glycol I,000 succinate (PLA-TPGS) nanoparticles (NPs) in phosphate-buffered saline $(\mathrm{pH}=7.4)$ at $37^{\circ} \mathrm{C}$

Abbreviation: PLGA, poly(lactic-co-glycolic acid).

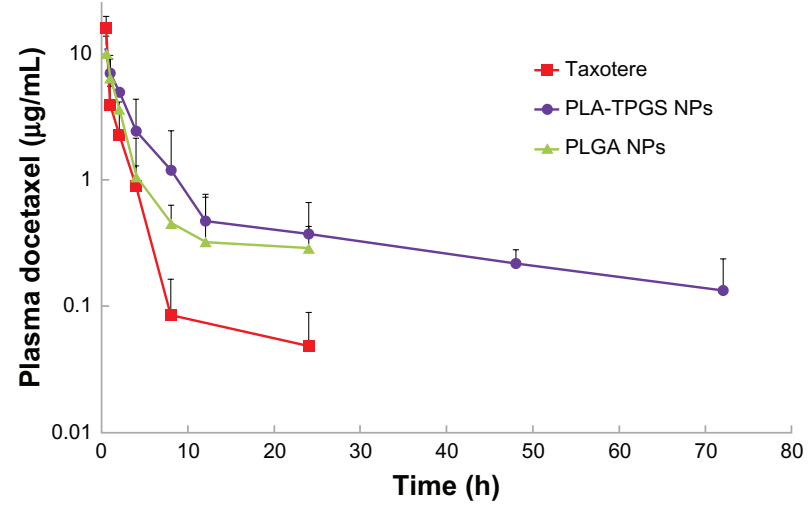

Figure 7 Pharmacokinetic behavior after intravenous injection at a dose of docetaxel (DTX) $10 \mathrm{mg} / \mathrm{kg}$ to Sprague Dawley rats of Taxotere and DTX-loaded poly(lacticco-glycolic acid) (PLGA) and poly(lactide)-D- $\alpha$-tocopheryl polyethylene glycol 1000 succinate (PLA-TPGS) nanoparticles $(n=4)$.

Abbreviation: NPs, nanoparticles.

Table 8 Pharmacokinetic parameters in rats after iv injecting of Taxotere and DTX-loaded nanoparticles at a dose of $10 \mathrm{mg}$ DTX/kg $(n=4)$

\begin{tabular}{lllll}
\hline Parameters & Unit & Taxotere $^{\circledR}$ & $\begin{array}{l}\text { PLA-TPGS } \\
\text { NP }\end{array}$ & PLGA NP \\
\hline AUC $_{0-\mathrm{t}}$ & $\mathrm{mg} / \mathrm{L} * \mathrm{~h}$ & $23.4 \pm 4.2$ & $49.9 \pm 16 . \mathrm{I}^{1}$ & $28.0 \pm 4.3$ \\
$\mathrm{AUC}_{0-\infty}$ & $\mathrm{mg} / \mathrm{L} * \mathrm{~h}$ & $23.5 \pm 4.2$ & $57.9 \pm 14.0$ & $35.1 \pm 14.8$ \\
$\mathrm{MRT}_{0-\mathrm{t}}$ & $\mathrm{h}$ & $1.6 \pm 0.4$ & $13.6 \pm 2 . \mathrm{I}^{2}$ & $4.1 \pm 1.7^{3}$ \\
$\mathrm{MRT}_{0-\infty}$ & $\mathrm{h}$ & $\mathrm{I} .7 \pm 0.5$ & $29.4 \pm 20.4$ & $8.0 \pm 7.8$ \\
$t_{1 / 2}$ & $\mathrm{~h}$ & $2.1 \pm 1.2$ & $27.9 \pm 14.9^{1}$ & $4.4 \pm 3.6^{4}$ \\
$\mathrm{CL}$ & $\mathrm{L} / \mathrm{h} / \mathrm{kg}$ & $0.4 \pm 0.1$ & $0.2 \pm 0 . \mathrm{I}^{2}$ & $0.3 \pm 0.1$ \\
$\mathrm{~V}$ & $\mathrm{~L} / \mathrm{kg}$ & $\mathrm{I} .4 \pm 1.0$ & $7.8 \pm 5.3$ & $1.6 \pm 0.8$ \\
$\mathrm{~T}_{\max }$ & $\mathrm{h}$ & 0.5 & 0.5 & 0.5 \\
$\mathrm{C}_{\max }$ & $\mathrm{mg} / \mathrm{L}$ & $\mathrm{I} 5.9 \pm 4.9$ & $\mathrm{Il} .0 \pm 2.4$ & $10.2 \pm 1.6$ \\
\hline
\end{tabular}

Notes: ${ }^{\prime} P<0.05$ vs Taxotere; ${ }^{2} P<0.01$ vs Taxotere; ${ }^{3} P<0.01$ vs PLA-TPGS nanoparticles; ${ }^{4} P<0.05$ vs PLA-TPGS nanoparticles.

Abbreviations: $\mathrm{AUC}_{0-\mathrm{t}}$, area under the plasma concentration time curve from time 0 to $\mathrm{t} ; \mathrm{MRT}_{0-\mathrm{t}}$, mean residence time from time 0 to $\mathrm{t} ; t_{1 / 2}$, the elimination half-life; $\mathrm{CL}$, total body clearance; $\mathrm{V}$, volume of distribution; $\mathrm{C}_{\max }$ and $\mathrm{T}_{\max }$ are the maximum docetaxel concentration and the corresponding. time, respectively; DTX, docetaxel; PLA-TPGS, poly(lactide)-D- $\alpha$-tocopheryl polyethylene glycol 1000 succinate; PLGA, poly(lactic-co-glycolic acid); NP, nanoparticle. 


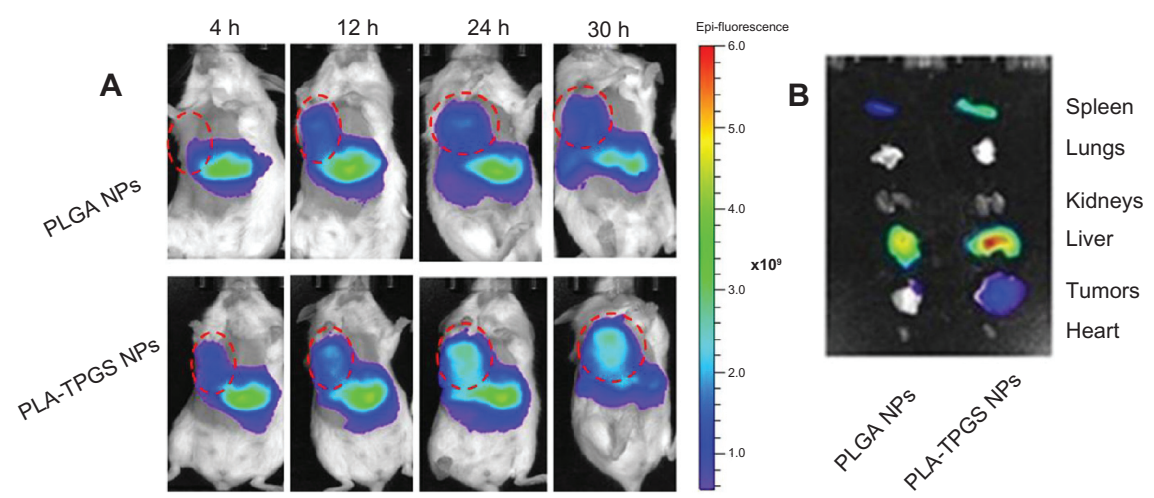

Figure 8 (A and B) Biodistribution of docetaxel-loaded nanoparticles. (A) In vivo images of H22 tumor-bearing mice after intravenous injection (dashed circles indicate tumors). (B) Ex vivo images of tumors and organs of $\mathrm{H} 22$-bearing mice killed at 30 hours.

Abbreviations: PLA-TPGS, poly(lactide)-D- $\alpha$-tocopheryl polyethylene glycol 1000 succinate; PLGA, poly(lactic-co-glycolic acid); NPs, nanoparticles; h, hour.

post injection, while limited fluorescence was observed in those of the PLGA group. The fluorescence signals of DIRloaded PLA-TPGS nanoparticles were clearly observed on the abdomen in the first 4 hours, and even increased as time elapsed. After 30 hours, the DIR accumulation in tumors of the PLA-TPGS nanoparticle-treated group was still higher than that of the PLGA nanoparticle-treated group. This also demonstrated that DIR-loaded PLA-TPGS nanoparticles have a better tumor distribution than PLGA nanoparticles. The ex vivo image of excised organs (Figure 8B) confirmed
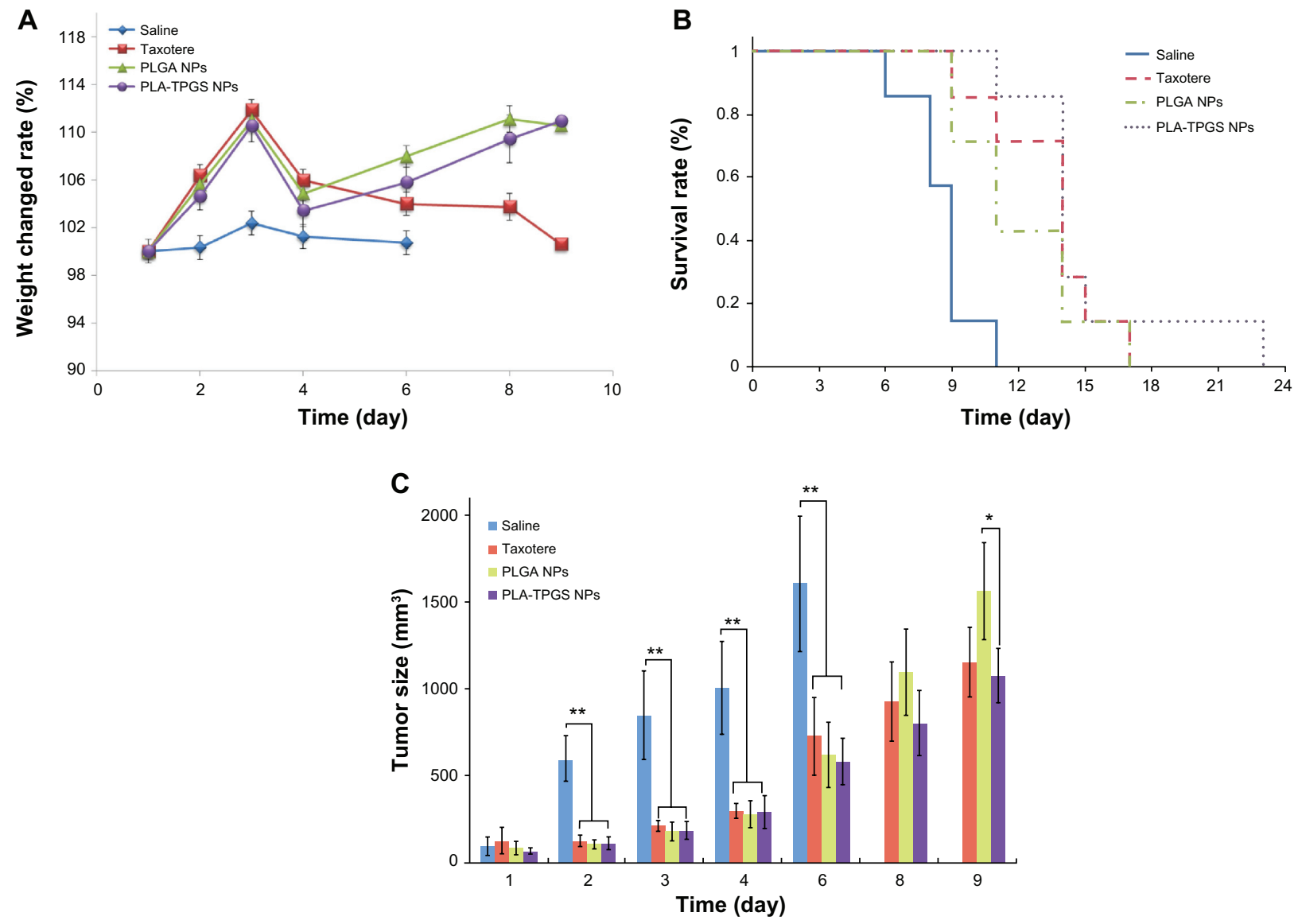

Figure 9 (A-C) In vivo antitumor efficiency of Taxotere and docetaxel-loaded poly(lactic-co-glycolic acid) (PLGA) and poly(lactide)-D- $\alpha$-tocopheryl polyethylene glycol I000 succinate (PLA-TPGS) nanoparticles $(n=7)$. (A) Weight changes of tumor-bearing mice; (B) survival rate of $\mathrm{H} 22$-bearing mice; $(\mathbf{C})$ relative tumor-growth ratio $(* P<0.05$, **P $<0.0$ I).

Abbreviation: NPs, nanoparticles. 
the higher fluorescence accumulation in the tumors of the PLA-TPGS nanoparticle-treated group compared with that of the PLGA nanoparticle group. These results further proved the selective accumulation of PLA-TPGS nanoparticles in hepatic cancer. The highest fluorescence intensity of liver and spleen was also observed for PLA-TPGS nanoparticles in 30 hours.

\section{Tumor-growth inhibition}

It has been clarified that DTX-loaded PLA-TPGS nanoparticles can prolong the blood circulation time of DTX. The antitumor efficacy of nanoparticles was further explored on H22 cell-bearing mice, as shown in Figure 9. Although all the groups showed tumor inhibition as opposed to the saline control group (at days 2, 3, 4, and 6, $P<0.01$ for Taxotere, DTX-loaded PLA-TPGS NPs, and PLGA NPs versus saline), DTX-loaded PLA-TPGS nanoparticles exhibited the best effect on tumor inhibition and safety, with minimal change in body weight during treatment. Taxotere-treated mice exhibited a significant loss in body weight. DTX-loaded PLA-TPGS nanoparticles showed a better effect than that of PLGA nanoparticles on day $9(P<0.05)$. Furthermore, the mean survival rate increased remarkably with DTX-loaded PLA-TPGS nanoparticle treatment compared to that of the DTX-loaded PLGA nanoparticle- and Taxotere-treated groups. These results confirmed that DTX-loaded PLATPGS nanoparticles exhibited potential for tumor-growth inhibition. The inhibition is nevertheless not as efficient as previously demonstrated on HT-29 human colon cancers. ${ }^{18}$ This may be attributed to the fact that DTX is not especially efficient in treating hepatic cancers. ${ }^{39,40}$ It still demonstrated that DTX-loaded PLA-TPGS nanoparticles can be used in treating hepatic cancer. It was also worth noting that although DTX-loaded PLA-TPGS nanoparticles showed a higher pharmacokinetic property than Taxotere, their tumor-inhibition result was not statistically significant.

\section{Conclusions}

In this paper, DTX-loaded PLGA and PLA-TPGS nanoparticles were fabricated with SPG membrane technology by optimization of various parameters, including surfactant type and concentration in aqueous phase, the volumetric ratio of organic to aqueous phase, transmembrane cycles and pressure, membrane-pore size, and polymer type. EE and DLE reached $64.5 \% \pm 2.7 \%$ and $38.8 \% \pm 5.6 \%$ for PLGA nanoparticles and $81.8 \% \pm 4.5 \%$ and $48.4 \% \pm 3.3 \%$ for PLA-TPGS nanoparticles, respectively. Particle sizes were around $300 \mathrm{~nm}$ with uniform structures. This demonstrated that the SPG membrane emulsification technique can be used in pilot studies of polymeric nanoparticles with good drug-entrapment efficiency and recovery. It can also be used to improve the preparation of nanoparticles in further experiments. The nanoparticles obtained by this method can realize a sustained release of entrapped drug. The antitumor activity, pharmacokinetics, and molecular imaging results showed the advantages of PLA-TPGS nanoparticles compared to the normally used PLGA nanoparticles. The PLA-TPGS nanoparticles increased the distribution of loaded drug in the tumor and extended drug-circulation time to more than 72 hours. This demonstrated the great potential of mass production of PLA-TPGS nanoparticles and antitumor treatment as a drug-delivery system.

\section{Acknowledgments}

This research was supported by the National Basic Research Program of People's Republic of China (973 Program, 2012CB932500), NSFC (81241103 and 21204024), and Innovative Fund of HUST (2012TS004). The authors thank Professor Xiangliang Yang and Jinyan Zhou for their help in using the image-analysis device in the analysis center of Huazhong University of Science and Technology, and Fanling Gong at the Institute of Process Engineering, Chinese Academy of Sciences, for her helpful advice. We are also grateful to the master's student Yuling Bao for assistance in animal tests.

\section{Disclosure}

The authors report no conflicts of interest in this work.

\section{References}

1. Dreicer R, Klein EA. Preliminary observations of single-agent docetaxel as neoadjuvant therapy for locally advanced prostate cancer. Semin Oncol. 2001;28(4 Suppl 15):45-48.

2. Aapro M. The scientific rationale for developing taxoids. Anticancer Drugs. 1996;7 Suppl 2:33-36.

3. Engels FK, Mathot RA, Verweij J. Alternative drug formulations of docetaxel: a review. Anticancer Drugs. 2007;18(2):95-103.

4. Baker J, Ajani J, Scotté F, et al. Docetaxel-related side effects and their management. Eur J Oncol Nurs. 2009;13(1):49-59.

5. Bissery MC, Nohynek G, Sanderink GJ, Lavelie F. Docetaxel (Taxotere): a review of preclinical and clinical experience. Part I: preclinical experience. Anticancer Drugs. 1995;6(3):339-355.

6. Masareddy RS, Joshi VG, Sutar RS, Yellanki SK. Nano drug delivery systems - a review. Int J Pharm Sci Res. 2011;2(2):203-216.

7. Tan S, Li X, Guo Y, Zhang Z. Lipid-enveloped hybrid nanoparticles for drug delivery. Nanoscale. 2013;5(3):860-872.

8. Liu F, Feng L, Zhang L, Zhang X, Zhang N. Synthesis, characterization and antitumor evaluation of CMCS-DTX conjugates as novel delivery platform for docetaxel. Int J Pharm. 2013;451(1-2):41-49.

9. Mu L, Seow PH, Ang SN, Feng SS. Study on surfactant coating of polymeric nanoparticles for controlled delivery of anticancer drug. Colloid Polym Sci. 2004;283(1):58-65. 
10. Kataoka K, Harada A, Nagasaki Y. Block copolymer micelles for drug delivery: design, characterization and biological significance. Adv Drug Deliv Rev. 2001;47(1):113-131.

11. Pillai O, Panchagnula R. Polymers in drug delivery. Curr Opin Chem Biol. 2001;5(4):447-451.

12. Kumari A, Yadav SK, Yadav SC. Biodegradable polymeric nanoparticles based drug delivery systems. Colloids Surf B Biointerfaces. 2010;75(1): $1-18$.

13. Zhang Z, Feng SS. Nanoparticles of poly(lactide)/vitamin E TPGS copolymer for cancer chemotherapy: synthesis, formulation, characterization and in vitro drug release. Biomaterials. 2006;27(2):262-270.

14. Hrkach J, Von Hoff D, Ali MM, et al. Preclinical development and clinical translation of a PSMA-targeted docetaxel nanoparticle with a differentiated pharmacological profile. Sci Transl Med. 2012;4(128): 128-139.

15. Zhang Z, Tan S, Feng SS. Vitamin E TPGS as a molecular biomaterial for drug delivery. Biomaterials. 2012;33(19):4889-4906.

16. Mu L, Feng SS. PLGA/TPGS nanoparticles for controlled release of paclitaxel: effects of the emulsifier and drug loading ratio. Pharm Res. 2003;20(11):1864-1872.

17. Mu L, Feng S. Vitamin E TPGS used as emulsifier in the solvent evaporation/extraction technique for fabrication of polymeric nanospheres for controlled release of paclitaxel (Taxol). J Control Release. 2002;80(1):129-144.

18. Zhang Z, Lee SH, Gan CW, Feng SS. In vitro and in vivo investigation on PLA-TPGS nanoparticles for controlled and sustained small molecule chemotherapy. Pharm Res. 2008;25(8):1925-1935.

19. Zhang Z, Feng SS. Self-assembled nanoparticles of poly(lactide)vitamin E TPGS copolymers for oral chemotherapy. Int J Pharm. 2006;324(2):191-198.

20. Gan CW, Feng SS. Transferrin-conjugated nanoparticles of poly (lactide)-D- $\alpha$-tocopheryl polyethylene glycol succinate diblock copolymer for targeted drug delivery across the blood-brain barrier. Biomaterials. 2010;31(30):7748-7757.

21. Wee Gan C, Chien S, Feng SS. Nanomedicine: enhancement of chemotherapeutical efficacy of docetaxel by using a biodegradable nanoparticle formulation. Curr Pharm Des. 2010;16(21):2308-2320.

22. Nakashima T, Shimizu M, Kukizaki M. Membrane emulsification by microporous glass. Key Eng Mater. 1992;61:513-516.

23. Hwang T, Park TJ, Koh WG, Cheong IW, Choi SW, Kim JH. Fabrication of nano-scale liposomes containing doxorubicin using Shirasu porous glass membrane. Colloids Surf A Physicochem Eng Asp. 2011;392(1):250-255.

24. Wei Y, Wang Y, Wang L, Hao D, Ma G. Fabrication strategy for amphiphilic microcapsules with narrow size distribution by premix membrane emulsification. Colloids Surf B Biointerfaces. 2011;87(2): 399-408.

25. Khayata N, Abdelwahed W, Chehna M, Charcosset C, Fessi H. Preparation of vitamin $\mathrm{E}$ loaded nanocapsules by the nanoprecipitation method: from laboratory scale to large scale using a membrane contactor. Int J Pharm. 2012;423(2):419-427.
26. Sheibat-Othman N, Burne T, Charcosset C, Fessi H. Preparation of pHsensitive particles by membrane contactor. Colloids Surf A Physicochem Eng Asp. 2008;315(1):13-22.

27. Liu W, Yang XL, Ho WS. Preparation of uniform-sized multiple emulsions and micro/nano particulates for drug delivery by membrane emulsification. J Pharm Sci. 2011;100(1):75-93.

28. Nakashima T, Shimizu M, Kukizaki M. Particle control of emulsion by membrane emulsification and its applications. Adv Drug Deliv Rev. 2000;45(1):47-56.

29. Kukizaki M, Nakashima T. Acid leaching process in the preparation of porous glass membranes from phase-separated glass in the $\mathrm{Na}_{2} \mathrm{O}-\mathrm{CaO}$ $\mathrm{MgO}-\mathrm{Al}_{2} \mathrm{O}_{3}-\mathrm{B}_{2} \mathrm{O}_{3}-\mathrm{SiO}_{2}$ system. Membrane. 2004;29(5):301-308.

30. Joseph S, Bunjes H. Preparation of nanoemulsions and solid lipid nanoparticles by premix membrane emulsification. J Pharm Sci. 2012;101(7):2479-2489.

31. Charcosset C, Limayem I, Fessi H. The membrane emulsification process - a review. J Chem Technol Biotechnol. 2004;79(3):209-218.

32. Cheng J, Teply BA, Sherifi I, et al. Formulation of functionalized PLGAPEG nanoparticles for in vivo targeted drug delivery. Biomaterials. 2007;28(5):869-876.

33. Tian R, Wang LY, Wu J, et al. Preparation of uniform-sized PLGA microspheres and microcapsules by Shirasu porous glass membrane emulsification technique. Chin J Proc Eng. 2009;9:754-762. Chinese.

34. Akamatsu K, Ikeuchi Y, Nakao A, Nakao S. Size-controlled and monodisperse enzyme-encapsulated chitosan microspheres developed by the SPG membrane emulsification technique. J Colloid Interface Sci. 2012;371(1):46-51.

35. Li X, Tian X, Zhang J, et al. In vitro and in vivo evaluation of folate receptor-targeting amphiphilic copolymer-modified liposomes loaded with docetaxel. International J Nanomedicine. 2011;6:1167-1184.

36. Galindo-Rodríguez SA, Puel F, Briançon S, Allémann E, Doelker E, Fessi H. Comparative scale-up of three methods for producing ibuprofen-loaded nanoparticles. Eur J Pharm Sci. 2005;25(4): 357-367.

37. Oh DH, Balakrishnan P, Oh YK, Kim DD, Yong CS, Choi HG. Effect of process parameters on nanoemulsion droplet size and distribution in SPG membrane emulsification. Int J Pharm. 2011;404(1):191-197.

38. Ma Y, Zheng Y, Zeng X, et al. Novel docetaxel-loaded nanoparticles based on PCL-Tween 80 copolymer for cancer treatment. Int $J$ Nanomedicine. 2011;6:2679-2688.

39. Liu Q, Li R, Zhu Z, et al. Enhanced antitumor efficacy, biodistribution and penetration of docetaxel-loaded biodegradable nanoparticles. Int J Pharm. 2012;430:350-358.

40. Zhu Z, Li Y, Li X, et al. Paclitaxel-loaded poly(N-vinylpyrrolidone)-bpoly( $\varepsilon$-caprolactone) nanoparticles: preparation and antitumor activity in vivo. J Control Release. 2010;142(3):438-446.
International Journal of Nanomedicine

\section{Publish your work in this journal}

The International Journal of Nanomedicine is an international, peerreviewed journal focusing on the application of nanotechnology in diagnostics, therapeutics, and drug delivery systems throughout the biomedical field. This journal is indexed on PubMed Central, MedLine, CAS, SciSearch ${ }^{\circledR}$, Current Contents ${ }^{\circledR} /$ Clinical Medicine,

\section{Dovepress}

Journal Citation Reports/Science Edition, EMBase, Scopus and the Elsevier Bibliographic databases. The manuscript management system is completely online and includes a very quick and fair peer-review system, which is all easy to use. Visit http://www.dovepress.com/ testimonials.php to read real quotes from published authors. 